\title{
Do we weep for Cordelia?
}

\section{Elisa Galgut}

To cite this article: Elisa Galgut (2003) Do we weep for Cordelia?, South African Journal of Philosophy, 22:3, 268-276, DOI: 10.4314/sajpem.v22i3.31374

To link to this article: http://dx.doi.org/10.4314/sajpem.v22i3.31374

\section{Published online: 28 Oct 2013.}

Submit your article to this journal $\pi$

LII Article views: 6

Q View related articles ¿ 


\title{
Do we weep for Cordelia?
}

\author{
Elisa Galgut \\ Department of Philosophy \\ University of Cape Town \\ Private Bag \\ Rondebosch 7701 \\ E-mail: <egalgut@ humanities.uct.ac.za>
}

'It is ... exactly because Hecuba is nothing to us that her sorrows are so suitable a motive for a tragedy.' Oscar Wilde

\begin{abstract}
Much of the contemporary debate concerning the nature and role of fictive emotions has argued that we do feel garden-variety emotions for fictional characters; the puzzle has been to account for this, given our knowledge of their fictional status. In this paper I argue that many of the emotional responses we have towards fictional characters are nothing like the emotions we feel in ordinary life. The implications for our engagement with literary fictions are subsequently examined.
\end{abstract}

For the past quarter of a century the aesthetics community has addressed Radford's ${ }^{1}$ puzzle regarding emotional responses to fictional characters. Why, indeed, are we moved by the fates of Anna Karenina, Little Dorrit, Cordelia, Oedipus? The answers have come in an assortment of guises: empathy, make-believe, simulation, imaginative identification, 'thought theories', and so on. The working assumption has been that we do feel 'garden-variety' emotions for fictional characters - we pity Anna, weep for Cordelia, despise Iago and fear for Oedipus. And this, surely, seems plausible enough - only those with no literary sensibilities, or with over-cultivated formalist ambitions, can fail to be moved by the hopes and despairs of these characters. Much of the recent work in aesthetics has been to explain how, in the absence of such seemingly necessary constituents, such as beliefs, garden-variety emotions are possible. So Walton, ${ }^{2}$ for instance, maintains that fictions generate make-beliefs, which function in certain relevant respects like ordinary beliefs, and which allow for the generation of emotions whose targets are fictional entities. There has been some debate concerning the nature of such make-believe emotions: on some interpretations, Walton could be understood as maintaining that make-believe pity, although it's an emotion all right, is a different sort of emotion from ordinary pity. After all, my pity for Cordelia does not give rise to many of the beliefs and actions that pity for a real person does. But this gives rise to the problem that, if we distinguish make-believe emotions from regular ones in this way, there is a difficulty in characterizing the nature of the former. Emotions are identified partly in terms of their functional roles; if the claim is that the functional role of

1 Radford 1975.

2 See Walton 1978, 1990, and in Hjort \& Laver 1997: 37-49. 
make-believe pity differs vastly from that of regular pity, then on what grounds do we claim to have make-believe pity ${ }^{3}$ Much of the discussion concerning the nature of fictive emotions has tried to show how make-believe emotions generated by fiction, such as my pity for Cordelia, are not intrinsically different from ordinary emotions felt in the course of daily living. The attempt has been to close the gap between our fictive and real life experiences in order to provide a seamless account of our emotions. And there is good reason for this; Radford's paradox shows us to be irrational in an area that is central to our lives, and solving the paradox is thus inherently worthwhile. More importantly, perhaps, is that emotional states generated by works of fiction resonate in ways that are relevant to our moral selves, and this would seem to bear witness to the claim that fictive emotions are not different in kind from ordinary emotions. After all, it seems that if literature has anything to say to us, it does so in virtue of deepening our understanding of and empathy for others. The value of tragedy, or of Henry James or Jane Austen, lies partly in the ability of such works to move us genuinely - to move us in ways which deepen our understanding of ourselves as persons, with moral responsibilities towards other persons.

This so-called 'seamless' account, which characterizes fictive emotions as either a subset of garden-variety emotions, or as equal to them in kind, chimes with our intuitions: my compassion for Cordelia feels to me like genuine compassion, not withstanding the objection that 'feels' are not sufficient to differentiate emotions. And this compassion has other similarities to ordinary compassion: it makes me concerned for Cordelia's welfare; I wish to defend her against the accusations of Lear, protect her from the machinations of her sisters, and save her from her unhappy fate. And yet there is something different about this compassion of mine. When Cordelia dies, I am not tortured by feelings of regret; I neither mourn, nor am melancholic. On the contrary, I may feel a strange sensation of elation upon leaving the theatre. The traditional problem of tragic pleasure confronts us with these contradictions. I want to argue that perhaps we've gotten it (partially) wrong: our pity for Cordelia is nothing like ordinary pity. Generalised, the claim is that many of our emotions towards fictional characters are nothing like our emotions towards real human beings. Literary characters do not engender feelings that normally arise in the course of daily life; we respond to the likes of Cordelia and Hecuba in ways that take us out of the range of the ordinary. Our 'pity' towards Cordelia lacks many of the features of regular pity: there is no desire to alter her fate, and, though we may be moved to tears, we are moved to the heights of pleasure as well. On leaving the theatre, we may dwell on the characters and their plights, but there is no sense of 'if only'. It might be argued that our pity for Cordelia lacks many of the features of garden-variety pity because it is directed onto a fictional character. "Of course we don't dwell on 'what might have been' in our experience of watching King Lear," the critic might say. "It's because we are aware of the representational nature of the play." But this objection misses the point: it is precisely that whatever the cause (and mimesis may play a crucial role) - the emotional experience is intrinsically different. The critic might respond by saying that the difference between regular pity and make-believe pity is found simply in the differences of their intentional objects; these differences account for the disparity between the two, but it's not enough to class them as different emotions. My response to this is that it does seem

3 For a fuller discussion, see Neill 1991. 
to me that the differences between my pity for my ailing grandmother, and my pity for Cordelia, are sufficiently great to distinguish them as emotions of different kinds. Emotions must play sufficiently similar functional roles in order to qualify as the same kinds of emotions, and my 'pity' for Cordelia is too unlike garden-variety pity to justify being referred to by the same term. An important reason for this is that the character of Cordelia is so unlike that of a real human being that she is immediately removed from a normal frame of reference. She is, in some respects, as terrifying in her steadfastness as Lear is in his impetuousness. Her measured argument regarding her love for Lear ('Why have my sisters husbands, if they say / They love you all?' I:i:98-99) smacks of psychological implausibility. Characters of tragedy are often so far removed from ordinary life that identification and empathy seem impossibly difficult. Oedipus, Lear, Cordelia are writ large - they tower above us mortals. No one thinks we cannot respond emotionally towards the figures of God and Satan in Paradise Lost, and here, if anywhere, the usual arguments for identification and simulation must seem implausible. Milton's masterpiece succeeds precisely because he is able to present us with characters larger than life; we cannot feel that they are 'just like us' (at least, not without suffering from the kind of hubris that would, by its mere possession, prevent empathy). Differences between ourselves and many characters of fictions are reflected too in their actions: patricide and incest are the order of the day in Greek tragedy, acts of pathos with which the audience must surely not identify (at least not without the benefit of years of psychoanalytic therapy). Aristotelian injunctions aside, the heroes and heroines of tragedy are different from us in key respects, however much we are supposed to identify with them. And these key differences ensure, I maintain, that the emotions we feel for the characters of tragedy are not - cannot be - the same as the emotions we feel for ordinary people. The claim is often made that we run an 'off-line' act of simulation, whereby we imagine ourselves in the characters' situations, and, instead of forming beliefs, performing actions and feeling emotions, we form 'make-beliefs', perform imaginative activities, and feel make-believe emotions. In other versions of the story, ${ }^{4}$ we imaginatively identify with a reader of a true report. In either case, the implication is that the characters with which we identify are creatures like ourselves, characters we just might have the fortune (or otherwise) of meeting at the local grocer's. This is a necessary condition for empathy, and the thesis is that it is in virtue of this empathy gained through 'off-line' processes of simulation that we have emotional responses towards fictional characters. ${ }^{5}$ I want to argue that we cannot account for many of our fictive emotions in this way: this road to empathy is blocked by more than an ageing king and his bodyguards.

This may sound like a radical thesis, although I hope to show that it is not. I also want to introduce a word of caution: I am not maintaining that no fictional characters inspire in us ordinary emotions. Certainly much literature - especially so-called 'realist' genres - does precisely that. My thesis is more limited in scope, and refers only to some literary works. But lest the reader wonder why she should take such a limited thesis seriously (after all, almost any thesis can be made about some literary work or other), I want to maintain that the literary works to which I refer are mostly the great

4 Most notably that of Currie 1990, and in Hjort \& Laver 1997: 63-77.

5 Some philosophers argue that it is in virtue of acts of simulation that we are able to feel empathy for our real-life friends and neighbours. 
works of 'the canon' ${ }^{6}$ In other words, it seems to me that many of the central and seminal works of literary fiction inspire in us emotions beyond and different from the ordinary, and I am intrigued, not only why this is the case, but wherein lies the value. For it is often maintained, in many discussions about the 'worth' of literature, that the likes of Homer and Shakespeare appeal to a common humanity, and herein lies their significance. In her discussion of Henry James, ${ }^{7}$ for instance, Martha Nussbaum writes of the importance of literature for the development of the virtues. It is in the very specificity of an image that moral salience lies; literary description allows moral recognition in a way that could not be gained through mere paraphrase.

Moral knowledge, James suggests, is not simply intellectual grasp of propositions; it is not even simply intellectual grasp of particular facts; it is perception. It is seeing a complex concrete reality in a highly lucid and richly responsive way; it is taking in what is there, with imagination and feeling ... If [Maggie's father] had grasped the same general facts without these responses and these images, in all their specificity, he wouldn't really have known her (p 521).

If indeed literature gives us a unique lens through which to perceive morally salient features of a situation, it must also provide us with a unique way of feeling. For the reader becomes sensitive to the moral dilemmas of fictional characters in virtue of responding emotionally in certain ways. These emotional responses are, I would think, necessary conditions for moral recognition. And then the question becomes: what are these emotional responses, and how do works of literature engender them? And if, as I intend to argue, many of the emotions we feel towards fictional characters are nothing like the sorts of emotions we feel for real humans, wherein lies the value of literature? It may seem some sort of confusion to argue both that the value of literature lies in the values it gives us in dealing with ordinary life and its vicissitudes, and to insist that the emotions engendered by literary texts are not the sorts of passions one can ordinarily expect to undergo.

What is the nature, then, of our engagement with fictional characters? I would like to enter the arena by way of a discussion of the notion of the Kantian sublime. The experience of the sublime arises in the presence of phenomena which transcend the limits of the imagination. In perceiving a towering mountain, for instance, the mind cannot picture (either in perception or in imagination) the full presence of the phenomenon, and the subject feels overwhelmed. This is why the sublime carries with it feelings of unease or disquiet - there is a sense that one could so easily be obliterated by the encounter. The sublime presents the self with an awareness of its own limitations as an imaginative being. There is, however, a sense of pleasure associated with the experience of the sublime - a so-called secondary pleasure. This pleasure arises because the self's rational capacity is able to comprehend the nature of the object (in this case, the immensity of the mountain), and is thus able to assert its authority: the supremacy of reason over sense experience is emphasised, and this, for Kant, brings feelings of reassurance. There is, I think, another kind of pleasure that the sublime brings, and this is to be found in the very awareness of the limitations of the imagination. It is only in the

6 I do not think that the canon is either exhaustive or indeed inclusive of all the types of works to which my explorations may apply. I am also aware of the debate surrounding the very notion of a literary canon, but I don't wish to enter into that debate here.

7 Nussbaum 1985: 516-529. 
seeing of boundaries that one discovers the shape of the object, ${ }^{8}$ and the sublime thus brings with it a species of self-knowledge. Unlike the experience of the beautiful, which allows the self to experience a sensation of merging with the object, ${ }^{9}$ the sublime forces on the subject the awareness of itself as separate from the perceived phenomena.

How is this relevant to the question of the tears I weep for Cordelia? I would like to argue that great literature is often sublime in just the way that Kant understands it namely, certain works, like King Lear, and Paradise Lost, overwhelm the reader. They present her with characters and situations which lie outside the scope of daily experience, and they invite her to follow paths untrodden by her imagination. This, of course, is not the whole story: I shall not attempt to give an account of our emotional experiences towards such works as King Lear solely - or even predominantly - in terms of the sublime. Unlike many works of fantasy or horror, texts of the 'canon' cannot simply be explored under the rubric of the literary 'sublime'. For one thing, they're not completely beyond the scope of what can be imagined. If this were the case, the reader would simply be mystified - or merely entertained - by the fictions. Aristotle noted that a hero of a tragedy must be like ourselves: it is vital that the reader or audience be able to identify (or at least feel able to identify, which may amount to the same thing), in some respect or other, with the hero - not in that I think that I am like Lear qua Lear, or like Cordelia qua Cordelia, but rather in that I identify Cordelia and Lear with myself, qua person. So in this sense, works of literature do involve ordinary emotions. The opening scene of the play shows us what seems to be a family drama, one with which, although we may not be able to identify in terms of scale (who amongst us has had kingdoms divided on our behalf?), we are certainly able to understand by drawing parallels with our own smaller family dramas. So when Lear says that he has divided 'In three our kingdom; and 'tis our fast intent / To shake all cares and business from our age', the audience, young and old, is able to understand the premise of the scene that follows, and becomes emotionally involved in the proceedings. We read correctly the insincere flattery of Goneril and Regan, and worry about the fate of Cordelia.

But - and this too Aristotle noted - the heroes ( or characters) of tragedy are also more than we could ever be: not only are they usually kings, or demi-gods, or even God himself, but their sins and their virtues are greater than those (often, perhaps, different in kind from those) we ordinary mortals experience. Aristotle was right to contend that the fatal flaw, or hamartia, is a necessary condition for tragedy, and the reason is this: it is the hamartia which allows the hero to transcend the bounds of ordinary life and places him or her in the realm of literature. Some commentators think of hamartia as a virtuous quality gone astray, much in the way that a cancerous tumour is the excessive growth of ordinary cells. This is a helpful analogy to the extent that it illustrates the kind of connection the reader feels towards the hero: the hero is like me, but more so, and it is this tension that provides the foundation for the kinds of emo-

8 Socrates makes this point in his emphasis on the value of awareness of one's own ignorance: in knowing the limits of my understanding, I am able to see the outline of my self. It is only then that I can begin the project of understanding and self-discovery.

9 The history of aesthetics, especially in the $18^{\text {th }}$ Century, reflects the twofold nature of the experience of the beautiful - beauty is seen neither as a (special) property of an object, nor as a purely personally subjective quality of the observer, but as an experience that arises from a meeting of the two. 
tions we feel towards literary characters. There must be a thread that connects the audience to the tragic hero; without it, we have mere grotesqueness or caricature. In the character of the hero or heroine, we are led out of ourselves, but always via an initial process of identification: we move from feelings of empathy, pity and other 'garden variety' emotions to feelings of sublimity, to 'aesthetic' emotions beyond the range of day-to-day experiences. So hamartia is not simply a character flaw that is the cause of the hero's downfall: it is, rather, the very condition that allows the hero to enter the realm of the literary (or the tragic). One cannot say 'if it weren't for his fault, the fate of Oedipus would have been different', for Oedipus would not have been Oedipus without the fault - not in the sense that the fault makes psychological sense, but rather because the fault is that which takes Oedipus out of the very realm where folk psychology operates. Oedipus becomes a literary figure in virtue of hamartia - it is the defining quality of the literary in the genre of Greek tragedy. We must, of course, generalise this notion beyond the genre of tragedy, and say that it is in virtue of psychological difference or extremism of some kind or other that is the mark of the literary character under examination.

Another mark of difference between ourselves and literary fictions is that, as readers of literature, we are struck by the inevitability of the fates of the characters. We know, with more or less certainty, what are to be the fortunes of Lear and Cordelia, of Oedipus, of Satan. Genre dictates much of this, as does the fact that many of the stories of literature are well known to their audiences. I would even go so far as to say that it is because of, rather than despite, their familiarity that these works are so moving. Ordinary fiction, on the other hand, relies for its emotional impact on the creation of expectations in the reader; but we don't read (and re-read) Oedipus and Paradise Lost in order to find out what is going to happen, at least not in the ordinary way of 'find out'. Literary characters are slaves to their stories; there is an absence of free will in their actions, and this immediately removes them from the realm of reality. This is reflected in their speech and behaviour:

Lear: $\quad$... what can you say to draw

A third more opulent than your sisters? Speak.

Cor: $\quad$ Nothing, my lord.

Lear: Nothing?

Cor: Nothing.

Lear: $\quad$ Nothing will come of nothing: speak again.

The refrain 'nothing' echoes relentlessly through the play. This exchange illustrates (at least) two issues: the psychological implausibility or extremism of both Cordelia and Lear, and the importance of placing their actions within the larger context of the play as a whole. What I mean by the latter point is not simply that the actions of fictional characters are constrained by the plots that write them, but rather that the reader has (must have) a sense of these constraints. We know, even before they happen, the consequences in Act V of the speeches in Act I, and this knowledge determines our emotional response to the unfolding drama. This sense of inevitability is missing from our ordinary emotional responses, and it has the sense of imbuing even innocent remarks and gestures with importance. 
What, then, is the nature of our emotional response to fictional characters, and how is this of value? I have argued elsewhere ${ }^{10}$ that emotional responses are constructed in ways ordinary emotions are not. We pity Cordelia partly because of her fate, but also partly because Shakespeare's language - its rhythm, its imagery - moves us in very particular ways. The fate of Cordelia in the hands of a lesser poet would simply not be as moving. There are, then, it seems, at least two broadly different ways in which our tears for Cordelia (if we shed any) differ from ordinary tears of pity: the first is that this 'pity' is shaped by aesthetic factors - language, imagery, construction of the plot and the second is that the character of Cordelia defies folk-psychological plausibility. I would like to gesture in the direction of a large claim about the effects literature has on us, and it is that great works of literature - and their characters - take us out of ourselves before bringing us back, and we return with a heightened sense of who we are, or of what we are capable. I'm not sure that I mean this in any grandiose sense sometimes we may be appalled at what we find. Aristotle signalled us in this direction with his much-debated notion of katharsis, and my argument may be seen as operating within that tradition, very broadly construed. Lear and Cordelia and Oedipus are phantastic figures, in the psychoanalytic sense: they resonate with Unconscious feeling and fantasies. ${ }^{11}$ This is one of the reasons that the familiarity of the stories, the inevitability of the fates of the characters, is not an impediment to our enjoyment. On the contrary, a sense of familiarity is precisely what chimes with us. One of the characteristics of the Unconscious is that of timelessness, and so a sense of familiarity with a well-known story, or a recognition that takes the form 'I know where this is going', will mirror more closely Unconscious structures. This goes for the characters too: one of the important lessons we learn from psychoanalysis is that figures we internalise are not fully rounded humans: they are parts of significant others, split off from their real-life counterparts, and developed in odd or extreme ways. The internalised fatheror mother-figure is never taken in whole, as it were - as Klein taught us, the 'good' mother is a separate entity from the 'bad' mother, and Freud's superego is an aspect of the forbidding parent whose fearful characteristics are magnified. So the psychological implausibility of Cordelia - her relentless avowal of truth unmarred by compassion and the stubborn madness of Lear are features of personae, not persons, of caricatures, not characters. Once again, this allows a strong and immediate identification with Unconscious processes, which is where, I want to argue, the power of much literature lies.

Much of what I am arguing is not new, ${ }^{12}$ but it is a discussion that seems absent from much of the philosophical debate surrounding fictive emotions. There has, to my mind, been too much of an emphasis on the cognitive nature of emotions, and aestheticians have skewed much of the debate in the hopes of showing how aesthetics is consistent with recent developments in cognitive psychology. Thus the endeavour has been to illustrate how engagement with fiction fits into an overall understanding of the

10 Galgut 2001.

11 I would like to venture a bold thesis - the topic for a different paper - that the value of literature lies in its ability to shape the very contents of the Unconscious by allowing us to internalise structures of experience.

12 I refer the reader, for instance, to Jonathan Lear's excellent paper 'Katharsis' (Lear 1998) in the philosophical literature, but much discussion of the relationship between stories and phantasy can be found in the psychoanalytic literature - most famously Uses of Enchantment (Bettelheim 1978). 
mind as essentially 'rational'; fictive emotions are shown to be not all that different from ordinary emotions - they have the same structure, albeit different intentional objects - and these garden-variety emotions have important connections with our moral selves. I would like to suggest, on the contrary, that much of this discussion is wrong-headed: fictive emotions (at least some of them) are, in central and important ways, nothing like ordinary emotions. Moreover, I would like to argue - although this is not the place - that the claim that our emotions are cognitive and structured like beliefs is wrong, or incomplete, and we lose much if we attempt to assimilate all of our psychological theory to a cognitive and rational one. Part of this discussion will involve looking more fully at the way that our fictive emotions are structured, for if it is the case that they cannot be understood on a cognitivist belief-desire model, we need something new in its place. Here the similarities with the experience of the sublime may prove useful, for the imagination must play a crucial role, and, in the absence of a coherent theory of its workings, we must move forward in piecemeal fashion. The nature and construction of metaphor will, I think, be central, for it is my contention that fictive emotions are structured differently from ordinary emotions. They cannot be analysed as sophisticated kinds of beliefs (beliefs + desires + feelings), and one of the important roles that literature plays lies in the way that it structures, through literary form, our internal lives. The mind attempts to understand itself partly through the use of metaphor, and poetry, whose main business is metaphor, gives expression, albeit indirectly, to this attempt. Literature does not merely examine the use of metaphor as representative of certain mental processes; it also utilises metaphor, and in its utilisation allows the reader to experience the emotional process which is being articulated. Hence we are brought to insights regarding our states of mind - insights which would not be possible in the absence of the work of art. This explains why the literary emotions are ones which cannot be felt in ordinary life; they are, in part, second order emotional states, which contain, simultaneously, their expression, as well as an understanding of the conditions of this expression. ${ }^{13}$ And herein too lies much of the value of literature; for even though we may never, in real life, undergo these literary passions, we do gain insight into our emotional lives. This discussion may have some bearing on recent discussion in the theory of narrative: much of the discussion there seems dominated by a causal theory of narrative, which also assumes a 'rational' or cognitive mental framework. If I am right, such a view will be inadequate to explain the power literature has to move us. If the imagination is structured differently from cognition, then a story will move us, not so much in terms of the coherence of its plot, but for different reasons, reasons which, I suspect, we must tease out from individual texts. Providing an analysis of fictive emotions and narrative theory may turn out to look something like presenting an analysis of the trajectory of a neurotic symptom, whose aetiology makes sense in the light of the particular meaning of certain acts or symbols.

\section{Bibliography}

Bettelheim, B. 1978 The Uses of Enchantment Harmondsworth: Penguin.

Currie, G. 1990 The Paradox of Caring in Hjort \& Laver 63-77.

13 Similarities with Collingwood's expression theory will be noted by the reader. 
Currie, G. 1990 The Nature of Fiction Port Chester: Cambridge Univ. Press.

Galgut, E. 2001 The Poetry and the Pity: Hume's Account of Tragic Pleasure British Journal of Aesthetics 41(4): 411-424.

Hjort, M. \& Laver, S. (Eds). 1997 Emotion and the Arts New York: Oxford Univ. Press.

Lear, J. 1988 Katharsis Phronesis 33(3): 297-326.

Neill, A. 1991 Fear, Fiction and Make-Believe The Journal of Aesthetics and Art Criticism, Winter: 47-56.

Nussbaum, M. 1985 Finely Aware and Richly Responsible The Journal of Philosophy 82: 516-529.

Radford, C. 1975 How Can I Be Moved by the Fate of Anna Karenina? Proceedings of the Aristotelian Society: Supplement, 49: 67-80.

Walton, K. 1978 Fearing Fictions The Journal of Philosophy, 75: 5-27.

Walton, K. 1990 Mimesis as Make-Believe: On the Foundations of the Representational Arts. Cambridge, Massachusetts: Harvard Univ. Press.

Walton, K. 1997 Spelunking, Simulation, and Slime: On Being Moved by Fiction in Hjort \& Laver, 37-49. 